\title{
Geçici hayvan barınaklarının genel durumları ve sorunlarına ilişkin bir değerlendirme: Ege bölgesi örneği
}

\author{
Aysun KOÇ ${ }^{1}$, Pınar AYVAZOĞLU DEMIR² \\ ${ }^{1}$ Adnan Menderes Üniversitesi Veteriner Fakültesi Veteriner Hekimliği Tarihi ve Deontoloji Anabilim Dalı, Işıklı, Aydın/TÜRKIYE \\ ${ }^{2}$ Kafkas Üniversitesi, Veteriner Fakültesi, Hayvancılık Ekonomisi ve İşletmeciliği Anabilim Dalı, Paşaçayırı, Kars/TÜRKIYE
}

\section{Anahtar Kelimeler: \\ hayvan geçici bakımevi \\ mevzuat \\ sokak hayvanları \\ sorunlar \\ veteriner hekim}

Key Words:

animal rescue shelters

legislation

street animals

problems

veterinarian

Geliş Tarihi: 09.04.2019

Kabul Tarihi: 11.06.2019

Yayın Tarihi: 30.06.2019

Makale Kodu: 551445

Sorumlu Yazar:

P. AYVAZOĞLU DEMIR

(pinardemir80@hotmail.com)

ORCID:

A. KOÇ: 0000-0003-0856-9069

P. AYVAZOGLLU DEMIR: 0000-0002-7010-

0475

\begin{abstract}
ÖZ
Bu çalışma; Ege Bölgesindeki belediyelerde geçici hayvan bakımevlerinde çalıșan veteriner hekimlerin görüş ve önerilerini belirlemek amacıyla yapılmıștır. Araştırma materyalini; Ege Bölgesi’ndeki belediyelere ait geçici hayvan bakımevlerinde çalışan ve araştırmaya katılmayı gönüllü olarak kabul eden veteriner hekimler ile yapılan görüșmeler olușturmuștur. Elde edilen bilgiler doğrultusunda geçici bakımevlerine gelen hayvan sayısının 2015 yılına göre 2018 yılında 2,7 kat arttığ1 ve gelen hayvanların \% 62,9'nun köpek olduğu belirlenmiştir. Çalışmada hayvanların sağlık durumuna göre bakımevlerinde kalış sürelerinin ortalama 19,3 gün (min:5, max:45) olduğu tespit edilmiştir. Çalıșmaya katılan veteriner hekimlere göre geçici bakımevinde çalıșmanın bașlıca zorlukları arasında; hayvanseverlerin tutum ve davranışları, bakımevlerinin teknik-fiziki ve tıbbi donanımlarının yetersiz oluşu, iş yoğunluğu ve siyasi faktörler gelmektedir. Yapılan çalışmada geçici bakımevine veya sokağa bırakılan hayvanların \%88 gibi önemli bir kısmının alışma dönemlerinin uzun sürdüğü ve psikolojilerinin bozulduğu belirlenmiştir. Sonuç olarak, geçici bakımevlerinde verilen hizmetlerin sistematik ve yeterli bir şekilde yürütülmesi adına mevcut koşullarının iyileştirilmesine yönelik hukuki düzenlemelerin yapılmasının yanı sıra toplumun da bilgi düzeyi ve duyarlılığının artırılması gerektiği söylenebilir.
\end{abstract}

An evaluation of the general situations and problems of temporary animal rescue shelters: the case of aegean region

\begin{abstract}
This study was conducted to determine the opinions and recommendations of veterinarians working in temporary animal care center of municipalities in Aegan region. Research material consists of interviews conducted with the veterinary surgeons who worked in the temporary animal care centers in the Aegean region and who voluntarily accepted to participate the study According to the information obtained, the number of animals arriving at temporary care centers increased by 2.7 times in 2018 compared to 2015 and $62.9 \%$ of the animals were found to be dogs. According to the health status of the animals, the duration of stay in the shelter was 19.3 days (min: 5, max: 45). According to the veterinarians participating in the study, the main difficulties of working in the care centers are the attitudes and behaviors of animal lovers, inadequacy of the technical-physical and medical equipment of the centers, the work intensity and the political factors. In the study, it was determined that part of $88 \%$ of the animals that were left to the shelter or the streets took long habituation period and their psychology adversely affected. As a result, it can be said that in addition to improving the existing conditions of the institutional structures in order to carry out the services provided in animal care centers in a systematic and adequate manner, the level of knowledge and sensitivity of society on this subject should also be increased.
\end{abstract}

\section{GİRİŞ}

Tarihin ilk dönemlerinden beri birbirini etkileyen insan-hayvan ilişkisi, değişen tüm koşullara bağlı olarak devam etmiştir. Zamanla modern yaşamların oluştuğu kentlerde; insan-hayvan birlikteliği aynı çatı altında sürdürülmüştür. Ancak sokaklarda yaşayan sahipsiz hayvanlar da, bu kentlerde yaşam zorluklarıyla karşı karşıya kalmışlardır. Türkiye'de sokaklarda yaşayan sahipsiz hayvanların karşılaştıkları zorlukların ve sorunların çözümü belediyelerin (yerel yönetim) sorumluluğunda yürütülmektedir (1).

Türkiye'de 1991 yılına kadar sadece belediyelerin görev ve sorumluluk alanına giren sahipsiz hayvanlar ile ilgili çalışmalarda, Çevre Bakanlığı’nın kurulmasından sonra bu Bakanlığa yasal çerçevenin hazırlanması, sahipsiz hayvanlar ile ilgili strateji ve planların yapılması ve denetim konularında görev verilirken; yerel yönetimlerin, gönüllü kuruluşlarla işbirliği içerisinde, sahipsiz ve güçten düşmüș hayvanların korunması için hayvan bakımevleri ve hastaneler kurması istenmiştir (2).

Belediye hizmetleri kapsamında "Geçici Hayvan Bakımevi" olarak adı geçen kurumlar, son yıllarda etkin bir şekilde hizmet vermektedir. Halk sağlığı ile çok yakından ilgili olan hayvan sağlı̆̆1; sokaklarda kontrolsüz yaşayan ve üreyen hayvanların denetimi noktasında oldukça önem arz etmektedir. Belediye 
hayvan bakımevleri genel çerçevede; hayvanlarda ki kontrolsüz üremenin önüne geçmek için uygun yaș aralığında olan hayvanları kısırlaştırmak, hayvanlardan insanlara bulaşan hastalıkların önüne geçmek için koruyucu-kurtarıcı önlemleri almak, yavru ve erişkin kedi-köpeklerin iç ve diş parazitlerinin tedavisini yapmak, erişkin kedi ve köpeklerin kulak küpeleme işlemi ile sahiplendirme işlemlerini amaç edinerek hizmet vermeye çalışmaktadır (1). Bahsi geçen bu hizmet alanları, son yıllarda hayvan sağlı̆̆1 ve hayvan hakları bakımında toplumda dikkat çekici bir hal almıştır. Bu bakımdan tedavi edici noktada paydaşları arasında varlığıyla birincil yerde duran veteriner hekimlere "Hayvanların Korunmasına Dair Uygulama Yönetmeliği1" çerçevesinde hem yasal, hem de mesleki uygulamada büyük görev ve sorumluluklar düşmektedir.

Belediyeler, hizmetlerini yasal maddelere dayanarak yürütürler: Bunlardan ilki, 23.07.2004 tarih ve 25531 say1 ile Resmi Gazete de yayımlanarak yürürlüğe giren Büyükșehir Belediyesi $\mathrm{Kanunu}^{2}$ dur. Bu kanun maddesinin ilgili bendinde; Büyükşehir Belediyelerinin hizmet ettiği bütünlük içerisinde; bölge parklar1, hayvanat bahçeleri, hayvan barınakları ve benzeri yerleri yapmak, yaptırmak, işletmek, işlettirmek şeklinde ki görev- yetki ve sorumluluklarını tanımlamıştır. Türkiye Belediyeler Birliği Mevzuatı kapsamında yer alan 09.10.2005 tarih ve 25961 say1l Resmi Gazete'de yayımlanarak yürürlüğe giren 'İl Özel İdaresi Ve Belediye Hizmetlerine Gönüllü Katılım Yönetmeliği" "nin ilgili bölümünde başıboş ve sahipsiz hayvanlara yönelik hizmetleri yapmak ya da gönüllü çalıştırmak esasıyla hizmetlerini belediyeler yürütmektedirler. Yine Türkiye Belediyeler Birliği’nin, 11.04.2007 tarih ve 26490 say1lı Resmi Gazete 'de yayımlanarak yürürlüğe giren; Belediye Zabita Yönetmeliği'‘’nin ilgili bölümünde de sağlıkla ilgili görevlere yer verilmiștir. Bu görevlerini, 3285 sayılı Hayvan Sağlığ1 ve Zabitası Kanununa ve ilgili yönetmeliklere dayanarak bir yerde hastalık ç1kması veya sebebi belli olmayan hayvan ölümlerinin görülmesi halinde bu yerleri geçici kordon altına almak, yetkililere bu konuda her türlü yardımı yapmak, imhası gereken hayvanların itlafina yardımcı olmak, bunların insan sağllğına zarar vermeyecek şekilde imhasını yaptırmak şeklinde belirlenmiştir. Diğer bir yasal dayanak da; Belediye Zabita Yönetmeliği'nde yer alan, 5199 sayılı Hayvanları Koruma Kanunu ${ }^{5}$ ile belediyelere, zabitanın görevleri içerisinde verilen yetkilerini kullanmasıdır.

Bu çalışma, sokak hayvanlarının rehabilite edilmesi ve hayvan sağlı̆̆1 kadar halk sağlığını da korumayı esas alan geçici hayvan barınak/bakımevlerinin, Ege Bölgesindeki genel durumunu ortaya koymak ve var olan sorunların belirlemek amacıyla yapılmıştır. Ekip çalışmasıyla yürütülen geçici hayvan bakımevi hizmetlerinin önemli ve ilk el paydaşı olan veteriner hekimlerin görüş ve önerilerinin yer aldığı bu çalışma ile sorunların çözümüne destek sunmak ve konunun öneminin vurgulanması hedeflenmiștir.

1 Resmi Gazete Tarih: 12.05.2006, Say1: 26166.

2 Resmi Gazete Tarih : 23/7/2004, Say1: 25531, Kanun Numaras1: 5216.

3 Resmî Gazete Tarihi: 09.10.2005 Resmî Gazete Sayısı: 25961

4 Resmî Gazete Tarihi: 11.04.2007 Resmî Gazete Sayısı: 26490

5 Resmi Gazete Tarih: 01.07.2004 Sayı: 25509, Kanun Numaras1: 5199

\section{GEREÇ ve YÖNTEM}

Araştırmanın materyalini, Ege Bölgesi'nde (Aydın, Afyonkarahisar, İzmir, Denizli, Kütahya, Manisa, Muğla, Uşak) bulunan il ve ilçe Aydın (Merkez, Söke, Kuşadası, Nazilli, Didim), İzmir (Işı1kl, Seyrek, Aliağa, Çeşme, Menderes, Bayraklı, Buca, Örnekköy, Karşıyaka), Denizli (Merkez, Çivril), Kütahya (Merkez), Manisa (Merkez, Kula), Muğla (Merkez, Ortaca, Bodrum, Milas, Marmaris, Dalyan, Turgutreis), Afyonkarahisar (Merkez, Emirdağ), Uşak (Merkez) belediyelerine ait geçici hayvan bakımevlerinde çalışan ve araştırmaya katılmayı gönüllü olarak kabul eden veteriner hekimler ile yapilan görüşmeler oluşturmuştur. Çalışmada; 2019 yılında belediyelere ait toplam 29 hayvan bakımevi/barınağı olup, 25’i (\%86,2) ile bakımevleri ve sahipsiz hayvanların mevcut durumlarına ilişkin anket çalışması yapılmıştır. Görüşmelerden edilen veriler, sıklık dağılımı ve/ veya yüzdeler şeklinde tablolar halinde sunulmuştur.

\section{BULGULAR}

Yapılan çalışmada bakımevlerinde çalışan 25 veteriner hekimin ortalama 40 yaşında (min:24, max:57) olduğu, ortalama 4,94 yıldır (min:1, max: 16 yıl) bakımevlerinde çalıştığ1 ve aylık ortalama gelirlerinin 4.955 TL (min:2.700, max:6.500) olduğu belirlenmiştir. "Bir veteriner hekim olarak bakımevleri/bar1naklarda çalıșmanın zorlukları nelerdir?” sorusuna katılımcılarin verdikleri cevaplar Tablo 1'de verilmiştir.

Tablo 1. Veteriner hekimlere göre barınakta çalışmanın zorluklar1

Table 1. Difficulties of working in a animal rescue shelter according to veterinarians

\begin{tabular}{lcc}
\hline Barınakta çalışmanın zorlukları & Frekans* & Yüzde \\
\hline $\begin{array}{l}\text { Hayvan severlerin barınaklara ilişkin } \\
\text { tutumları }\end{array}$ & 18 & 31.0 \\
Fiziki ve teknik donanımın yetersizliği & 10 & 17.2 \\
İş yoğunluğu & 10 & 17.2 \\
$\begin{array}{l}\text { Bütçe kısıtlı (Tıbbi ekipmanlar, teknik } \\
\text { personel, mama, yem) yetersiz }\end{array}$ & 7 & 12.1 \\
$\begin{array}{l}\text { Bulaşıcı hastalık riski ve hijyen sorunu } \\
\text { Siyasi nedenler }\end{array}$ & 7 & 12.1 \\
$\begin{array}{l}\text { *İlgili soruya birden fazla cevap verilmiştir, yüzdeler verilen cevap sayısı üze- } \\
\text { rinden hesaplanmıştır. }\end{array}$ &
\end{tabular}

Tablo 1 incelendiğinde, bakımevleri/barınaklarda çalışmanın başlica zorlukları arasında; hayvanseverlerin tutum ve davranışları, barınakların teknik-fiziki ve tıbbi donanımlanının yetersizliği, iş yoğunluğu, belediyelerce ayrılan bütçenin kısıtlı olması nedeniyle aşı, ilaç, mama ile gerekli ekipmanların sağlanamaması, teknik yardımcı personel yetersizliği ve siyasi nedenlerle veteriner hekimlere uygulanan mobbing gelmektedir.

Barınaklara gelen hayvanlara ilişkin uygulanan prosedürler hakkında elde edilen bilgiler doğrultusunda öncelikle ön muayenenin yapıldığ1, hasta ile sağlıklı hayvanların ayrılarak aşı yapıldığ1, hasta olanların tedavi edilip tekrar eski yerine bıra- 
kıldığı belirtilmiştir. Yapılan görüşmelerde, barınaklara gelen hayvanlara ilişkin uygulanan prosedürlerin, Hayvanları Koruma Kanunun'da belirtilen esaslara göre yapıldığı belirtilmiştir. Yapılan çalışmada bir hayvanın ortalama 19,28土10,47 gün (min:5, max:45) barınakta kaldığı belirlenmiş olup hayvanların barınakta kalma süreleri Şekil 1'de gösterilmiştir.

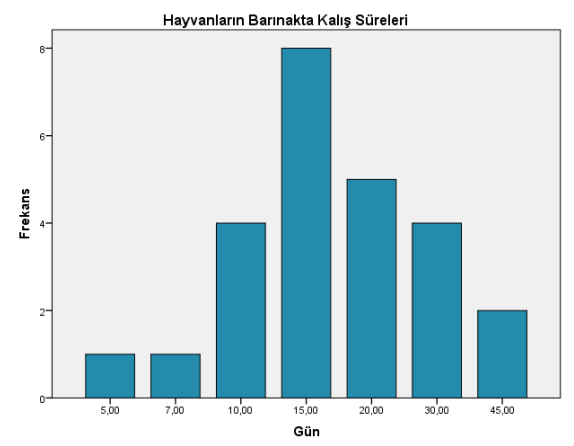

Şekil 1. Hayvanların barınakta kalış süreleri

Figure 1. Animals's duration of stay in rescue shelter

Çalışmada 25 barınağın 21'inde (\%84) gelen hayvanların \%83,3’ünün kısırlaştırılıp serbest bırakıldığ1 belirlenmiş olup, tekrar kontrolünü yapan bakımevlerinin oranı $\% 20$ olarak tespit edilmiştir. Yıllar itibariyle bakımevlerine gelen hayvan sayısı Tablo 2'de verilmiştir.

Tablo 2. Yillar itibariyle barınaklara gelen hayvan sayıs

Table 2. Number of animals coming to animal rescue shelters by years

\begin{tabular}{|c|c|c|c|c|c|c|}
\hline Yillar & $\underset{\text { say1s1 }}{\text { Minimum hayvan }}$ & $\begin{array}{c}\text { Maximum } \\
\text { hayvan sayıs1 }\end{array}$ & $\begin{array}{l}\text { Ortalama gelen } \\
\text { hayvan say1s1 }\end{array}$ & Std. Sapma & $\begin{array}{c}\text { Toplam } \\
\text { gelen hayvan } \\
\text { sayisi }\end{array}$ & $\begin{array}{c}1 \text { y⿺l öncesine } \\
\text { göre } \% \text { artiş }\end{array}$ \\
\hline 2015 & 62 & 8.339 & 2614.2 & 3305,63 & 13.071 & 100 \\
\hline 2016 & 415 & 4.600 & 3946.9 & 2733,51 & 26.092 & 99.6 \\
\hline 2017 & 418 & 7.222 & 4348.7 & 2613,04 & 31.575 & 21.0 \\
\hline 2018 & 600 & 8.500 & 2705.2 & 2634,90 & 35.168 & 11.4 \\
\hline
\end{tabular}

Tablo 2 incelediğinde, bakımevlerine 2015-2018 y1lları arasinda gelen toplam hayvan say1s1 105.906 olup; 2018 y1lında 2015 yılına göre 2,7 kat arttı̆̆1 görülmektedir. Çalışmada ayrica 2018 yilinda barinaklara gelen toplam 35.168 hayvanin \%37,1'ini kedilerin, \%62,9'nu ise köpeklerin oluşturduğu tespit edilmiștir. Yapılan görüşmelerden elde edilen veriler doğrultusunda bakımevine getirilen hayvanların geliş şekilleri ve yüzde oranları Şekil 2'de verilmiştir.

\section{Barınaktaki hayvanların geliş şekilleri}

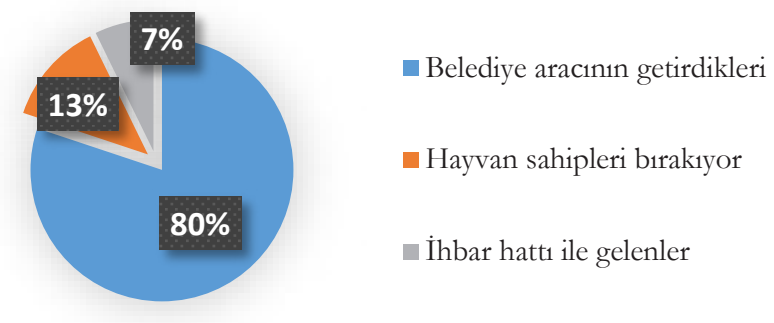

Şekil 2. Barınağa getirilen hayvanların geliş şekilleri

Figure 2. The arrival of animals brought to the animal rescue shelter
Sekil 2 incelendiğinde bakımevlerine gelen hayvanların \%80'nin belediye görevlileri tarafindan bulunup getirildiği görülmektedir. Hayvan sahipleri tarafindan birakilan hayvanların oranı ise \%13'dir. Barınakta çalışan sorumlu veteriner hekimlerden alınan bilgiler doğrultusunda hayvan sahiplerinin barınağa veya sokağa evcil hayvanlarını bırakma sebepleri Tablo 3’te verilmiştir.

Tablo 3. Hayvanların barınağa veya sokağa bırakılma nedenleri Table 3. The reasons for leaving of animals in the shelter or street

\begin{tabular}{lcc}
\hline Nedenler & Frekans* & Yüzde \\
\hline Bakım zorluğu & 16 & 28.1 \\
Yer değiştirme-taşınma & 13 & 22.8 \\
Çevrenin rahatsız olması & 12 & 21.1 \\
Hastalık-tedavi masrafları & 10 & 17.5 \\
Hayvanın yaşlanması & 6 & 10.5
\end{tabular}

*Illgili soruya birden fazla cevap verilmiştir, yüzdeler verilen cevap sayısı üzerinden hesaplanmıştır
Tablo 3 incelendiğinde, hayvanların sokağa ve/veya barınağa birakılmasının başlıca nedeni, bir hevesle satın alınan hayvanların bakımının zor gelmesidir. Özellikle Ege Bölgesi'nin sahil yerlerine getirilen hayvanların tatil dönüșü bırakılması, ev halkının ve/veya komşularının rahatsız olması, hastalık ve tedavi masrafları diğer önemli faktörlerdir. Katılımcılarla yapılan görüşmelerde sokağa ve/veya barınağa bırakılan hayvanların yeni yaşam koşullarına uyumlarına ilişkin elde edilen sonuçlar Tablo 4'te verilmiştir.

Tablo 4. Sokağa veya barınağa birakılan hayvanlanın uyumu

Table 4. Harmony of animals left on the street or shelter

\begin{tabular}{lcc}
\hline Uyum & Frekans & Yüzde (\%) \\
\hline Psikolojileri bozuluyor & 12 & 48 \\
Alışma dönemleri zor ve uzun sürüyor & 10 & 40 \\
Kısa zamanda alışıyorlar & 3 & 12 \\
\hline
\end{tabular}

Tablo 4 incelendiğinde sokağa/barınağa birakılan bu hayvanların önemli bir kısmının (\%88) alışma dönemlerinin uzun sürdüğü ve psikolojilerinin bozulduğu belirlenmiştir. Barınağa 
birakılan bir kedi ve/veya köpeğin ortalama 20 gün (min:10, max:60) sonra yeni yaşam koşullarına alışmaya başladı̆̆ı, ancak bu dönemde çok saldırgan ve depresif oldukları, iştah kaybı bildirilmiştir. Barınaktaki hayvanların sahiplenilmesine ilişkin veriler Tablo 5'de verilmiştir.

Tablo 5. Barınaktaki hayvanların sahiplenme durumları

Table 5. Ownership of animals in the animal rescue shelter

\begin{tabular}{|c|c|c|c|c|c|}
\hline $\begin{array}{l}\text { Barınaktaki hayvanlar sahipleniliyor } \\
\text { mu? }\end{array}$ & Frekans & Yüzde & $\begin{array}{l}\text { Barınağa bırakılan hayvanlar } \\
\text { tekrar sahipleniliyor mu? }\end{array}$ & Frekans & Yüzde \\
\hline Evet s1k s1k & 7 & 28 & Evet & 18 & 72 \\
\hline Ara sira & 9 & 36 & Hayır & 2 & 8 \\
\hline Nadiren & 9 & 36 & Bazen & 5 & 20 \\
\hline \multicolumn{3}{|c|}{ Genelde yavru kedi köpek mi tercih ediliyor? } & \multicolumn{3}{|c|}{ Genelde cins hayvanlar mi sahipleniliyor? } \\
\hline Evet & 20 & 80 & Evet & 20 & 80 \\
\hline Hayır & 5 & 20 & Hayır & 5 & 20 \\
\hline
\end{tabular}

Tablo 5 incelendiğinde, barınakların \%28'inde s1k s1k, \%36'sinda ara sıra hayvanseverlerin barınaktaki hayvanları sahiplendikleri belirlenmiş olup, hayvanseverlerin \%80 oranında yavru ve/veya cins hayvanları tercih ettiği tespit edilmiştir.

“Gözlem-bilgi ve tecrübelerinize dayanarak pet/sokak hayvanlarına, Hayvanları Koruma Kanunu kapsaminda bir hak ihlali olduğunu düşünüyor musunuz?” sorusuna katılımcıların \%80'ni evet, \%20'si hayır cevabını vermiştir. Karşılaşılan ihlallerde; 1. sırada sokak hayvanlarına psikolojik-fiziksel şiddet uygulanmas1, 2. sirada tedavi haklarından mahrum birakılmas1, 3. sirada sokak hayvanlarının zehirlenmesi ve 4. sirada cinsel istismar gelmektedir.

Veteriner hekimlerle yapılan görüşmelerde barınaklara ilişkin sorunların çözüm önerilerini önem sırasına göre sıralamaları istenmiştir. Verilen cevaplar 5199 sayılı Hayvanları Koruma Kanunun revize edilerek hayvan barınaklarının hayvan refahına uygun standartlarda inşa edilmesi; petshoplarda (kedi-köpek) satışının yasaklanması ve kurumlararası yetki ve denetim karmaşasının düzenlenmesi gerektiği şeklinde sıralanmaktadır.

\section{TARTIŞMA ve SONUÇ}

Sokak hayvanı; sahipsiz, sokakta yaşayan, sokakta doğmuş ya da evden atılmış başıboş hayvanlar (3) olup, son dönemde gerek sosyal medyada çıkan haberler, gözleri bakımevlerine çevirmiştir. Nitekim, şehirlerde yaşayan başıboș hayvanlar ile insanlar arasındaki etkileşimi sağlıklı boyutta tutarak halk ve hayvan sağlı̆̆ını güvence altına almak devletin sorumluluklarindan biridir (2).

Günümüzde, kentleşme süreci ile birlikte sahipsiz sokak hayvanlarının yaşam alanlarının daraldığı, düzenli ve yeterli beslenemedikleri ve gerek halk sağlı̆̆1 gerekse çevre sağlı̆̆ aç1sından sorunların arttığ1 söylenebilir (4). Yiğit ve ark (2016)'nın yapmış oldukları çalışmada; Türkiye'de sahipsiz, güçten düşmüş, terk edilmiş hayvanların barındırılması ve rehabilitasyonunu sağlamak üzere yaklaşık 200 tane hayvan barınağı, rehabilitasyon merkezi ya da (geçici) bakımevleri bulunduğu ve buralara gelen hayvan sayısının her geçen gün artığı bildirilmiştir. Yapılan bu çalışmada da, geçici bakımevlerine gelen hayvan sayısının son dört yıl verileriyle değerlendirildiğinde 2015 y1lına göre, 2018 y1lında 2,7 katlık bir artışta olduğu tespit edilmiştir.
Yapılan çalışmada, Ege bölgesindeki geçici bakımevlerindeki hayvanların \%62,9'nu köpeklerin oluşturduğu saptanmıştır. Köpek sayısının daha fazla olması, kedilerin kendi başlarına daha kolay idare edebilmeleri ve evde bakım oranlarının köpeklere nazaran daha fazla olmasıyla açıklanabilir. Nitekim, 102 pet hayvan sahibi ile yapılan anket çalışmasından (6), elde edilen verilere göre; katılımc1ların \%54,9'unun kedi, \%37,3’ünün köpek ve \% 7,8'inin hem kedi hem köpek besledikleri belirlenmiştir.

Yapılan bu çalışmada, bakımevlerinde çalışan veteriner hekim için hayvanseverlerin barınaklara ilişkin ön yargıları ve tutumlarının önemli bir sorun olduğu ifade edilmiştir. Özellikle sosyal medyada bilgilerin yanlış anlaşılması/yönetilmesi sonucunda oluşan sanal bilgi kirliliği nedeniyle veteriner hekimlerin hayvanseverler ile karşı karşıya geldikleri bildirilmiştir. Görüşmelerde ayrıca fiziki koşuların ve tıbbi donanımın yetersizliği ve kapasitenin üstünde hayvan sayısı nedeniyle oluşan iş yoğunluğu, ayrılan bütçenin yeteriz olmasına bağlı olarak aşı, mama masraflarının karşılanamaması, teknik personel sıkıntısı ve siyasi nedenlerle mobbing uygulamaları diğer önemli zorluklar arasında olduğu belirlenmiştir. Oysa, sokak hayvanlarının artıș hızına müdahale edilmesi, var olan hayvanların așılı ve sağlıklı olup olmadığının tespiti ve sokağa birakılan hayvanların sahiplendirilmesinde belediyelere ait barınaklar önemli bir role sahiptir. Yapılan görüşmelerde; bahsi geçen nedenlerden dolay1 bakımevlerinin istenen etkinlikte bir çalışma profili oluşturamadığ1 ifade edilmiştir.

Sokak hayvanlarına ilişkin etik değerler, onlara karşı tutum ve davranışları etkilemektedir. Olumsuz etik değerlerin olumlu değerlere dönüşmesi bu hayvanlara ilişkin bilinç ve duyarlılığın arttırılması ile geliştirilebilir (4). Bu bağlamda hayvan sahipleri tarafindan barınaklara birakılan hayvanların oranı ise $\% 13$ olup, katılımcı veteriner hekimlere göre hayvanların barınağa bırakılma nedenleri arasında; bakım zorluğu, yer değiştirme, komşuların ve/veya evdeki bireylerin şikâyetleri gelmektedir. Yapılan görüşmelerde özellikle Ege Bölgesi'nde yılın belirli dönemlerinde tatil amaçlı gelen insanların sahil beldelerinde edindikleri petleri, bu beldelerden ayrilırken geride biraktıkları 
belirtilmiştir. Oysa bir hevesle satın alınan, büyüdüklerinde, yaşlandıklarında, hastalandıklarında ya da yeterince "eğlenceli" bulunmadiklarında terk edilen binlerce kedi ve köpeğin, bugün ya sokaklarda ve/veya barınaklarda yaşam savaşı verdiği ve birçoğunun da yaşamlarını devam ettiremediği bilinmektedir. Nitekim barınak veteriner hekimleri ile yapılan görüşmelerde sokağa atılan bir kedi veya köpeğin ortalama 20 gün (min:10, max:60) sonra yeni yaşam koşullarına alışmaya başladıkları ancak bu dönem zarfinda psikolojilerinin bozulması nedeniyle çok agresif ve çok depresif oldukları, yeme - içmeden kesildikleri bildirilmiştir. Bununla birlikte sokaklardan barınağa getirilen hayvanlarda da ayrılmış kapalı kafes koşulları özgür hareket ettiği ortamlarından farklı bir alanda bulunmaları ve özgürlüklerinin daraltılması nedeniyle tepkisel davranışlar gösterebilmektedirler (7).

Hayvanların sahiplenme durumlarına ilişkin veriler irdelendiğinde; hayvanseverlerin özellikle yavru ve/veya cins hayvanları sahiplenmek istedikleri tespit edilmiştir. Bu duruma yavruların ev kurallarına daha kolay alışacağının düşünülmesinin ve cins hayvanların bir statü göstergesi olarak kabul edilmesinin yol açtığı düşünülmektedir. Bununla birlikte barınaktan cins hayvan edinmek isteyen hayvanseverlerin daha önce ev ortaminda yaşayan bir hayvanın bir sokak hayvanına göre yeni ev ortamına daha kolay alışabileceği düşüncesinin de bu tercihlerde etkili olduğu söylenebilir.

Veteriner hekimlerin \%80’i pet/sokak hayvanlarına, hayvan hakları yönünden bir hak ihlali yapıldığını düşündüğü belirlenmiştir. Katılımcıların yaşanan hak ihlallerine ilişkin yaptıklanı sıralamaya benzer olarak, Türkiye'de hayvan hakları ihlalleri ile ilgili yapılan bir çalışmada (8) yaşama mekânlarının daraltılması, beşeri üst yap1 unsurlarının yaygınlaşması, evcil veya doğal yaşama ortamlarına tekrar uyum sağlayamayacak durumda olan hayvanların dışarı atılması, sahipsiz hayvanları hiçbir neden yok iken imha etme - şiddete maruz birakılması gibi fiziksel müdahalelerin olduğu bildirilmiştir. Bu bakımdan, 1. Sahipsiz Hayvan Rehabilitasyon Çalıştayı'nda (9), 5199 Sayılı Hayvanları Koruma Kanunu'nda hayvan haklarını güvence altına alan ayrıntılara ve yasal yaptırımlara yer verilmesine rağmen özellikle sokak hayvanları ve barınaklara ilişkin konularda da kanunun yetersiz kalması nedeniyle revize edilmesi gerektiği belirtilmiștir. Nitekim veteriner hekimlerle yapılan görüșmelerde de, barınaklara ilişkin sorunların çözümüne ilişkin öneriler arasında 5199 say1l Hayvanlar1 Koruma Kanunun revize edilerek, hayvan barınaklarının hayvan refahı standartlarına uygun olarak inşaa edilmesi, petshoplarda (kedi-köpek) satıșının yasaklanıp, barınaklardan hayvan sahiplendirilmesi, hayvanlarını sokağa atanların engellenmesi için cezai yaptırımların artırılmas1 ve kurumlararası yetki karmaşasının önlenmesi gelmektedir.

Sonuç olarak; günümüzde sokak hayvanları, modern yaşam anlayışı içinde önemli bir sorun haline gelmiş olup hayvan barınaklarının mevcut koșulları ve ișleyiși konusunda kanun yap1cılara, belediyelere, gönüllü hayvanseverlere ve veteriner hekimlere büyük görev ve sorumluluk düştüğü kadar, toplumun her kesiminin bilinçlendirilmesi için kamu spotu ve eğitim seminerleri ile farkındalığ1 ve duyarlılığ artırmanın sorunların çözümünde etkili olacağı düşünülmektedir.

\section{KAYNAKLAR}

1. Çapar S, Demir R. Türkiye'de Büyükşehir Yapılanması ve 6360 Sayılı Kanuna Uygulayıcıların Bakışı. Türk İdare Dergisi. 2017:484,39-88.

2. Menteş Gürler M, Osmanağaoğlu Ş. Türkiye'de hayvanlar1 koruma kanununun tarihsel gelişimi. Kafkas Üniv Vet Fak Derg. 2009;15:325-330.

3. Kandır Hesna E. Sokakların yuvasız sakinleri, Göller Bölgesi (Burdur, Antalya, Isparta, Afyon). Ayrintı Dergisi. 2014;21:714.

4. Tamzök H, Kük M, Çobanoğlu N. Hukuki ve etik boyutlarıyla sokak hayvanları. Ankara Üniv Sosyal Bil Ens Derg. 2013;4:245-280.

5. Yiğit A, Aslım G, Özdemir HC, Sarıkaya M. Türkiye'de sahipsiz hayvan barınaklarının durumu üzerine bir araştırma. 18. Uluslararası Veteriner Hekimliği Öğrencileri Bilimsel Araştırma Kongresi Özet Kitab1, 26-28 Nisan 2016, İstanbul.

6. Demir P, Uğurlu Koç A. Pet hayvan (Kedi-köpek) sahiplerinin veteriner kliniklerine ilişkin beklentileri. İstanbul Üniv Vet Fak Derg. 2014;40:168-175.

7. Demirbaş Salg1rlı Y, Emre B. Stresin köpeklerde davranış üzerine etkileri. MAKÜ Sag Bil Enst Derg. 2015;3:34-42.

8. Ilgar R. Türkiye'de hayvan hakları ihlallerine coğrafi açıdan bakış. ÇÜ Sosyal Bil Enst Derg. 2007;16:347-360.

9. İstanbul Büyükşehir Belediyesi Gıda Tarım ve Hayvancılık Daire Başkanlı̆̆ (2016). 1. Sahipsiz Hayvan Rehabilitasyon Çalıştayı Raporu. İstanbul. 